\title{
EL ETHOS, DE LA RETÓRICA AL ANÁLISIS DEL DISCURSO. ANÁLISIS DE CASO: LA IMAGEN DE LAS FARC EN LAS CONVERSACIONES DE PAZ
}

THE ETHOS, FROM THE RHETORIC TO THE ANALYSIS OF THE DISCOURSE. CASE ANALYSIS: THE IMAGE OF FARC IN PEACE DIALOGUES

Por:

Teresita Vásquez Ramírezi

Magister en Comunicación Educativa

Docente: Unniversidad Tecnológica de Pereira

Tevara@utp.edu.co

Resumen: Algunos estudiosos del discurso han propuesto ciertos desplazamientos en la noción de ethos aristotélico que han hecho posible análisis más detallados a la hora de revisar la imagen de sí que construye el orador en su discurso. Desde la perspectiva de la semiótica discursiva se ha planteado ampliar esta noción a tres lugares del discurso en los que se configura la identidad discursiva: el enunciador, el enunciatario y el referente. Igualmente, se ha propuesto homologar las causas de la persuasión presentadas por Aristóteles, la sensatez, la virtud y la benevolencia, a las dimensiones cognitiva, axiológica y afectiva de los sujetos discursivos. En el análisis del ethos de las Farc nos proponemos dar cuenta de la funcionalidad de estos planteamientos.

Palabras claves: Ethos, discurso, axiología, cognición, afecto.

Abstract: Some discourse scholars have proposed certain shifts in the Aristotelian notion of ethos that have made possible more detailed reviews when checking the image of itself that he builds in his discourse. From the perspective of discursive semiotics, it has been considered extending this notion to three parts of the discourse in which the discursive identity is configured: the sender, the receiver and referent; equally, it has been proposed to approve the causes of persuasion presented by Aristotle, wisdom, virtue and benevolence, to the cognitive, affective and axiological dimensions of discursive subjects. In the analysis of ethos about FARC, we aim to mention the functionality of these approaches.

Keywords: Ethos, discourse, axiology, cognition, affection. 
¿De qué manera se presenta, pues, el orador? ¿De qué recursos se vale para parecer digno de confianza ante su auditorio?Según Aristóteles, tres son las causas que hacen persuasivos a los oradores; y su importancia es tal que por ellas nos persuadimos. Esas causas son:

"la sensatez, [phronesis], la virtud [areté] y la benevolencia [eunoia]. [...] Fuera de estas causas no hay ninguna otra.Y, por lo tanto, es forzoso que aquel que parezca tenerlas todas resulte ser un orador persuasivo para el auditorio”. (1990, págs.309-310).

Woerther (2007) en un rastreo minucioso que hace sobre el sentido del ethos en la obra de Aristóteles, hace notar que la recurrencia de los verbos 'aparecer' y 'parecer' pone en evidencia que las virtudes que conforman el ethos no son más que 'artefactos', incluso 'simulacros', lo que subraya el carácter engañoso de la retórica denunciado por Platón (pág. 208).

Ahora bien, veinticinco siglos después, diversos investigadores del lenguaje introducen la noción de ethos en los estudios del discurso; al hacerlo, conservan algunos planteamientos hechos por Aristóteles, pero al mismo tiempo provocan ciertos desplazamientos que hacen de esta categoría un componente de análisis mucho más complejo que el propuesto en la retórica. Haremos un breve y no exhaustivo recorrido por los principales aportes para situarnos un poco.

En 1984, Oswald Ducrot introduce, desde la pragmática semántica, la noción de ethos cuando plantea su teoría polifónica de la enunciación y cuestiona la unicidad del sujeto; de acuerdo con este planteamiento, «en un mismo enunciado hay presentes varios sujetos con status lingüístico diferente [...], entre los cuales se pueden distinguir el sujeto empírico, el locutor (L), el locutor lambda $(\lambda)$ y el enunciador (E)» (Ducrot, 1988, pág. 16). Nos detendremos solo en el locutor (L) para señalar el lugar que él le asigna al ethos.

Ducrot (1986) señala una primera distinción entre el sujeto hablante y el locutor: el hablante es el autor efectivo, el productor empírico del enunciado; como tal, este sujeto no interesa al lingüista semanticista por cuanto su preocupación no estriba en explicar las condiciones de producción del enunciado. Por su parte, el locutor es «un ser que, en el sentido mismo del enunciado, es presentado como su responsable, es decir como alguien a quien se debe imputar la responsabilidad de ese enunciado» (pág. 198).

La segunda distinción la hace en el interior de la noción de locutor, entre el locutor 'como tal' (denominado L) y el locutor como 'ser del mundo' (denominado $\lambda$ ). El locutor L es «el responsable de la enunciación, considerado únicamente en virtud de esta propiedad. El locutor $\lambda$ es un ser discursivo situado en el nivel referencial del enunciado, es decir, al cual se refiere el locutor L». (Ducrot, 1986, pág. 204). 
Ducrot atribuye el ethos al locutor (L), el locutor como tal:

Por ser fuente de la enunciación se ve ataviado con ciertos caracteres que, por contragolpe, tornan aceptable o rechazable esa enunciación. Lo que el orador podría decir de sí mismo en cuanto objeto de la enunciación, concierne en cambio a $\lambda$, el ser del mundo. (Ducrot, 1986, pág. 205).

Esta precisión relativa a la relación entre el ethos y el locutor $\mathrm{L}$, y no el locutor $\lambda$, es importante:

No se trata de las afirmaciones jactanciosas que puede emitir sobre su propia persona dentro del contenido de su discurso, afirmaciones que por el contrario arriesgan chocar al oyente, sino de la apariencia que le confieren la cadencia, la calidez o severidad de la entonación, la elección de las palabras. (Ducrot, 1986, pág. 205).

En consecuencia, podemos decir que mientras el locutor L construye una imagen de sí implícita en el discurso, el locutor $\lambda$ lo hace de manera explícita: yo soy esto, yo soy aquello. Por lo tanto, y de acuerdo a las aproximaciones que propone Serrano (2013), el locutor (L) puede ocupar dos lugares discursivos, el de enunciador y el de referente. Es esta imagen de sí, autorreferida, que él denomina ethos referido.

Por la misma época, Maingueneau (1984) orienta sus investigaciones en pragmática y en análisis del discurso y enfoca su trabajo sobre el ethos dentro de un marco que va más allá de los propósitos planteados por los estudiosos de la argumentación. En este sentido, sus investigaciones se centran no solo en discursos de interés eminentemente persuasivo, como aquellos que se inscriben en el dominio político, publicitario, filosófico, sino también en aquellos textos que, como las instrucciones, tienen el propósito de ganar un público.

Dos razones me han incitado a recurrir a la noción de ethos: su vínculo crucial con la reflexividad enunciativa y la relación entre cuerpo y discurso que ella implica. La instancia subjetiva que se manifiesta a través del discurso no se deja concebir solamente como estatuto o rol, sino como "voz", y más allá, como “cuerpo enunciante”. (Maingueneau, 1999. pág. 76).

La presentación del enunciador a través de su discurso lleva al enunciatario a un proceso de interpretación que le permite reconstruir el ethos o imagen proyectada; se trata de que el enunciatario, partiendo de las representaciones sociales propias de su medio y su cultura, configure una imagen o garante del enunciador a la que simultáneamente le asigna un carácter o unas cualidades psicológicas y un cuerpo que podría derivarse de su gestualidad y su manera de vestir, cuando se trata de una comunicación oral; si se trata de una comunicación escrita, el enunciatario, valiéndose de la tonalidad y del estilo del enunciador, puede, igualmente, asignar un cuerpo a esa voz. En este sentido, para Maingueneau el ethos no está solo ligado a la palabra oral y tampoco se limita al campo de la argumentación, sino que se hace extensivo a otros tipos de discurso. 
Ahora bien, Maingueneau vuelve sobre los trabajos presentados por Ducrot y retoma la distinción que éste hace entre el locutor $\lambda$ y el locutor L, e introduce la diferencia entre el ethos «dicho» y el ethos «mostrado»: el primero guarda relación con la imagen que el orador expresa directamente en su alocución al hacer un retrato de sí mismo o de otro como objeto referido, y el segundo el que da a entender a través de la manera como se expresa y de los saberes y valores que esgrime en su discurso.

Para Maingueneau, si bien es cierto que:

El ethos está crucialmente vinculado al acto de enunciación, no se puede ignorar que el público se ha construido también representaciones del ethos del enunciador antes incluso de que él hable. Por consiguiente, es necesario establecer una distinción entre ethos discursivo y ethos prediscursivo (o previo). (Maingueneau, 2004, pág. 205).

El primero corresponde a la denominación aristotélica, el ethos interno al discurso; el segundo, a la imagen del orador configurada por sus interlocutores a partir de sus actuaciones pasadas, su filiación institucional, su reputación, cuando se trata de personajes que hacen parte de la escena pública. Cuando el orador no se conoce, como puede suceder con un texto escrito, el lector puede conferirle, a través de las marcas expresivas, el género discursivo o su postura ideológica, un cuerpo y un carácter. Vale aclarar que el término «pre-discursivo» no debe entenderse como anterior y exterior al discurso, sino simplemente como anterior al acto discursivo producido aquí y ahora, en el presente de la enunciación.

Ruth Amossy, por su parte, plantea que en las relaciones intersubjetivas que tienen lugar tanto en espacios institucionales como en aquellos de la vida cotidiana, cada participante, al tomar la palabra, construye una imagen de sí y, precisa, esta presentación no se limita a ser una 'técnica aprendida' o un artefacto que el orador usa para mostrarse y crear una imagen artificiosa, puesto que en su arquitectura también intervienen de manera significativa actuaciones discursivas no deliberadas que escapan a la conciencia del orador. Es por esto que la construcción de una imagen de sí debe ser, en primera instancia, rastreada en las marcas subjetivas del lenguaje, i.e., las personas gramaticales, los pronominales, tiempos, espacios y otras marcas subjetivas que expresan reacciones valorativas:

Ellas pueden ser "afectivas" (expresan una reacción emocional), "evaluativas" (reflejan una competencia cultural) y “axiológicas" (conllevan un juicio de valor). Todas estas marcas lingüísticas contribuyen a la construcción de un ethos en la medida en que proyectan necesariamente en el discurso una imagen de la personalidad, de las competencias y de los sistemas de valores del locutor. (Amossy. 2010, pág. 109). 
De igual importancia, son los cruzamientos teóricos que ha realizado Amossy de los trabajos de sociólogos como Pierre Bourdieu y Erving Goffman con los planteamientos del ethos aristotélico y los aportes de los analistas del discurso, con la finalidad de proponer nuevos desplazamientos en la noción. En este sentido, para ella, la propuesta aristotélica, que concibe un ethos interno al discurso, puede ser complementada con la postura sociológica que sitúa el poder del discurso tanto en sus condiciones internas como en las condiciones sociales e institucionales externas.

En esa dirección, se inscribe su propuesta sobre el ethos previo, «imagen contextual del ser real, [que] no se confunde con la realidad de la persona, sino que consiste en la esquematización de una realidad preexistente» (Amossy, 2010, pág.77). Este tipo de esquematización o estereotipación se pone en evidencia a partir de las representaciones sociales que tiene la sociedad sobre sí misma; en este sentido, hace parte de un sistema de creencias desde el cual opera el individuo para leer su realidad. El ethos, pues, según Amossy, es indisociable de una imagen previa, estereotipada, ligada a un accionar, a unos comportamientos del sujeto portador de esta imagen, y por lo tanto, vinculada a la imagen que se construye en el discurso.

Volvamos nuevamente sobre el carácter tripartito del ethos aristotélico, configurado por la sensatez, la virtud y la benevolencia. La primera corresponde a una cualidad intelectual en la medida en que está ligada a la razón práctica; la segunda, a una cualidad axiológica, y la tercera a una cualidad afectiva. Partiendo de estas tres cualidades que Aristóteles propone como necesarias para la persuasión, Ekkehard Eggs (1999) las interpreta en este sentido: «Los oradores inspiran confianza, (a) si sus argumentos y sus concejos son competentes, razonables y deliberados, (b) si son sinceros, honestos, y equitativos y (c) si muestran solidaridad, bondad y amabilidad hacia sus oyentes» (Eggs, 1999, pág.41). Y señala que, si bien estas cualidades tienen un sentido moral, éste no deriva de un sistema de valores abstracto o de una fuerza interior del orador, sino que son propias de acciones deliberadas, reflexionadas y pensadas en función del éxito de los argumentos.

Ahora bien, a partir de esta lectura elaborada por Eggs, Serrano (2013) propone equiparar las causas de la persuasión propuestas por Aristóteles con las dimensiones del sujeto que plantea la semiótica discursiva, complejizando de esta manera la noción de ethos.

Así, la sensatez, que corresponde a una cualidad intelectual, es equiparada a la dimensión cognitiva del sujeto, en la que se pone a prueba el sistema de distinciones del orador, sus creencias, sus saberes, su cosmovisión y sus representaciones sociales.

Por su parte, la virtud, como cualidad ética, es cotejada con la dimensión axiológica, en la medida en que el sujeto actúa como un evaluador capaz de hacer estimaciones de acuerdo con un sistema de valores inscrito en la cultura de la que él participa.

Finalmente, la benevolencia está asociada a una disposición afectiva que se manifiesta en términos de euforia o disforia: la primera corresponde a una emoción positiva; la segunda, a una emoción negativa. Otras dos posiciones afectivas son la ambivalencia (emoción positiva y negativa) y la aforia, que es de hecho una neutralización de la emoción.

Serrano propone añadir a los anteriores un cuarto componente, el lingüístico, en la medida en que todo enunciador debe disponer de una lengua que le permita producir enunciados mediante los cuales se refiere al mundo y se dirige a un enunciatario. Este componente también fue considerado de gran importancia por Aristóteles: en el libro III de la Retórica plantea que «una de las materias esenciales que debe tratarse acerca del discurso concierne a la expresión» (1990, pág.477). En efecto, no solo es importante lo que se dice, sino también la manera como se dice. 
Los trabajos desarrollados hasta ahora en análisis del discurso conservan en parte la propuesta aristotélica de vincular el ethos al orador. No obstante, hemos visto que Maingueneau, al retomar la distinción que hace Ducrot entre locutor L y locutor $\lambda$, distingue a su vez entre el ethos mostrado y el ethos dicho: el primero, implícito, es el del orador; el segundo es el del actor al que éste se refiere de manera explícita.

Dado que todo orador se dirige a un auditorio, puede afirmarse que, en el discurso, se configura también una imagen de éste. A este respecto, Serrano propone como hipótesis de trabajo una concepción del ethos mucho más compleja, que consiste en su rastreo a partir de tres lugares discursivos de construcción de identidad, el del enunciador, el del enunciatario y el del referente:

Nos parece, pues, que hablar de construcción discursiva del sujeto no puede reducirse a la construcción del ethos del orador, sino que tiene que incluir las imágenes del auditorio y del referente. [...] es tradicional ligar el ethos siempre al orador; pero, dado que tanto el enunciatario como el actor enunciados son imágenes construidas en el discurso ¿no sería válido extender el uso del término y hablar del ethos del orador, el ethos del enunciatario y el ethos del actor? (Serrano, 2013).

Visualicemos esta distribución en el siguiente esquema:

Ethos enunciador

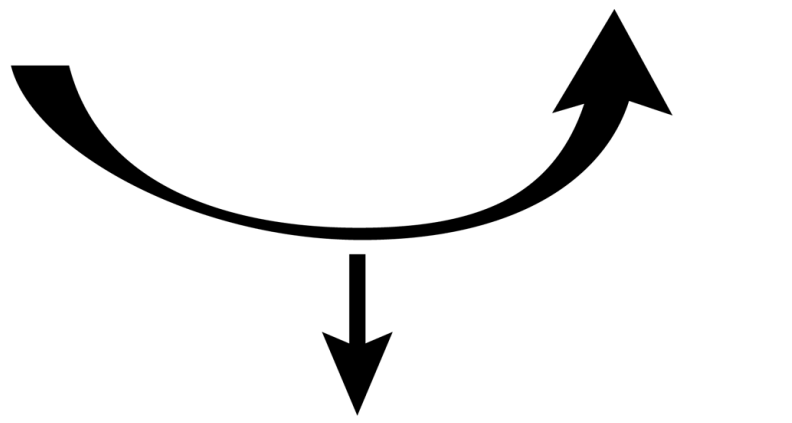

Ethos actor referido

La imagen de las Farc en las conversaciones de paz

Los colombianos hemos configurado un ethos previo de las Farc, que se ha fundamentado en diversos acontecimientos: por un lado, el fallido proceso del Caguán y el subsecuente recrudecimiento de la violencia que vino luego del rompimiento de las conversaciones; por otro, la ofensiva de deslegitimación que se inicia contra ellas al descalificarlas como movimiento guerrillero político, reforzada con una sanción por parte de la comunidad internacional al declararlas grupo narcoterrorista, descartando así cualquier salida negociada y restringiendo el abanico de la terminación de la confrontación a la vía militar. 
"El 20 de diciembre de 2007, la Unión Europea, Canadá y EEUU ratificaron la declaratoria de terroristas a los grupos violentos de Colombia y la Organización de Estados Americanos y la Organización de Naciones Unidas declararon terroristas sus actuaciones (Gallardo, 2010). Al comienzo de su primer mandato, el entonces presidente Uribe hizo la siguiente declaración:

Llegó la hora de quitarle a Colombia la pesadilla de estos bandidos sanguinarios [...] que tanto daño le han hecho a la Nación, aquí se acabaron las cofradías con esos bandidos, aquí se acabaron las tertulias con esos bandidos, aquí se acabó la receptividad para que estos bandidos continúen engañando al pueblo colombiano. Aquí lo único que hay es una decisión: desintegrar a las organizaciones de esos bandoleros, derrotarlos plenamente... Aquí no hay puntos medios. Frente al terrorismo una sola decisión: derrotarlo. Frente al terrorismo una sola decisión: desintegrarlo. Frente a esta caterva de bandidos una sola actitud: derrotarlos. (Uribe, Vélez. web.presidencia.gov.co).

Durante los ocho años del gobierno Uribe Vélez, la imagen de las Farc fue configurada a partir de este nuevo estatus: "grupo narcoterrorista"; el movimiento insurgente era reducido a la categoría de bandido y de terrorista y al mismo tiempo se negaba la existencia de una guerra civil o conflicto interno.

No se necesita, [dice Uribe], reconocer conflicto con terroristas para que las Fuerzas Armadas puedan válidamente tomar la iniciativa para atacar estos grupos. [...] Reconocer conflicto con terroristas es aceptarlos como actores políticos y abrir la puerta para que ellos pidan a terceros países el reconocimiento de beligerancia o abran oficinas allí como en el pasado." (Semana. com, 15 de mayo 2011).

Este es el ethos, ampliamente aceptado por la opinión pública, con el que las Farc llegan a las conversaciones de paz con el actual gobierno. Ahora bien, si las Farc quieren transformarse en un movimiento político y aspirar a la conquista del poder a través de la vía electoral deben, sin duda, reconfigurar su ethos político ante la opinión pública, de un lado, pasando de la acción militar a la acción discursiva y, de otro, cambiando el discurso de auto-justificación y de víctima por uno distinto en el que asuman su responsabilidad como victimarios y hagan propuestas que beneficien a los sectores de la sociedad que han sido sacrificados no solo por el abandono del Estado, sino a consecuencia de la guerra que se ha librado en sus territorios. 
De inmediato surge la pregunta ¿será posible para las Farc reparar la imagen con la que han llegado a la mesa de diálogo en La Habana? Miremos un ejemplo de la manera como ellos se presentan ante los colombianos:

Pero una década atrás no sólo se vino sobre Colombia y su pueblo una espantosa embestida militar, paramilitar, judicial, económica, política y social que hoy parece reconocerse como vana. También cayeron sobre nosotros como aves de presa, los propagandistas del régimen con su discurso difamatorio y venenoso. ¡Cuál de los más viles adjetivos no se lanzó contra quien asumiera una posición política próxima a nuestra palabra! ¡De qué estigma infamante no fuimos cubiertos quienes hicimos frente a la guerra y la violencia desatadas con frenesí desde el poder! ¡Cuál de los más horrorosos crímenes dejó de sernos imputado! También tan denigrante envilecimiento del lenguaje terminó siendo inútil. Volvemos a una mesa, reconocidos como adversarios militares y políticos, convidados y protegidos por quienes nos persiguieron, acompañados y avalados por la comunidad internacional. Definitivamente tanta manifestación de odio carece de sentido (Jiménez, 2012, Septiembre 5).

Si miramos atentamente la manera como las Farc se enuncian, vemos en primer lugar que se trata de un ethos referido o ethos dicho, porque ellas se narran así mismas y se convierten en objeto de su discurso para construir una imagen de sí: una característica de este tipo de estrategia consiste en recurrir a las marcas discursivas de la subjetividad con acento positivo.

Por otra parte, se presentan como sujetos de estado disjuntos de un poder hacer frente a la búsqueda de la paz, de un lado, porque tienen que enfrentar la decisión unilateral por parte de su adversario, el gobierno, quien rompe las conversaciones del Caguán; de otro, porque una vez asume el mandato Uribe Vélez, la batalla verbal arrecia en los medios de comunicación. Esta acción es evaluada por el grupo insurgente como un proceso de degradación de su imagen al calificarlo como "espantosa embestida".

Mediante la excesiva presencia de términos evaluativos en su discurso, las Farc se presentan como un sujeto de estado que padece un ataque verbal por parte de su adversario, e intentan señalar esto como una falacia, de tal manera que simultáneamente construyen la imagen del antisujeto como aves de presa. Además, señalan que la embestida no es solo contra ellas, el pueblo, sino también contra Colombia. Este hecho de nombrarse como pueblo es interesante porque su misma ambigüedad lleva subrepticiamente a identificar al pueblo con las Farc.

Como lo acabamos de ver, no solo se muestran como sujetos afectivos. También se presentan como sujetos axiológicos capaces de evaluar a su oponente, distanciándose de los valores que estos manejan; es decir, el antisujeto es construido como un competidor deshonesto que debilita a su oponente a través de la difamación, la calumnia, el estigma infamante, no a través de la verdad, sino a través de la vergüenza y la deshonra. Todas estas referencias contribuyen a la construcción de una imagen de víctimas. 
En adelante el movimiento guerrillero no dejará de presentarse como víctima de esta guerra, cada vez, de una manera más explícita:

[...] somos parte [además] de ese inmenso universo de víctimas del terrorismo de Estado y de la guerra, en general, impuesta por quienes detentan el poder y por quienes como sus voceros estipendiados o de oficio, generan las cortinas de humo con las que se pretende ocultar o excusar a los responsables fundamentales del desangre patrio. (Rainsford, BBC 2012, Septiembre 13).

Las Farc reconocen que el conflicto armado ha producido muchas víctimas, pero añaden que ellas mismas hacen parte de ese universo, consecuencia de las acciones de un Estado terrorista que ha provocado el desangre de la población, lo que a su vez ha sido ocultado por los medios de comunicación.

Si las Farc se declaran como víctimas, el movimiento contrario a esta declaración es: "No somos victimarios, como se nos ha querido hacer ver; es el Estado y quienes detentan el poder quienes imponen la guerra". En este caso el correlato que se infiere es: "Esta guerra no la hemos impuesto nosotros, nosotros la padecemos como padecemos sus injurias".

Otro ejemplo de ethos referido: Rueda de prensa en Oslo:

¿Ustedes estarían dispuestos a pagar cárcel en esta lucha por la paz, han contemplado esa posibilidad?

Nosotros somos luchadores, revolucionarios populares, nosotros no estamos cometiendo crímenes contra el pueblo. Respetamos mucho a los delegados del gobierno, pero respetarlos no quiere decir que no podamos entrar a debatir sus puntos de vista equivocados. Por ejemplo, la interpretación que hace De la Calle sobre las víctimas, ¿entonces resulta que es la guerrilla la victimaria? ¿Y dónde me dejan los 18.000 desaparecidos que pesan sobre los hombros del narco-presidente Uribe Vélez? (Rueda de prensa de las Farc en Oslo. 2012, Octubre 18).

A la pregunta por el secuestro y el narcotráfico, las Farc responden:

En febrero de este año el camarada Alfonso Cano dio unas declaraciones donde nosotros decimos que secuestro no hay por parte de las Farc [...] Sería violatorio de las orientaciones de las Farc. No es política de las Farc, y eso lo podemos comprometer (con) nuestra palabra ante el concierto internacional.

Nos acusan de narco-guerrilla y siempre hemos dicho: no tenemos nada que ver con el narcotráfico. [...]"una parte" de la resolución pasa por legalizar" las drogas, pero tenemos que resolver los temas que tienen que ver con la pobreza en el campo. (Rueda de prensa de las Farc en Oslo. 2012, Octubre 18). 
Este autorretrato exculpatorio es enérgicamente rechazado por los foristas:

Es repugnante, por decir lo menos, ver a estos terroristas asesinos, resentidos sociales, capaces de los peores crímenes como si fuesen legítimos representantes de los colombianos. [...]

Las Farc no sorprenden, son las mismas que siempre hemos conocido, no han cambiado nada de nada pero los testarudos del gobierno apoyados por un congreso igual de inepto y los medios de comunicación en manguala con los terroristas están a punto de entregarle el país a 10.000 miserables narco-asesinos.

Miremos otra intervención más reciente de las Farc:

"Hemos dicho que cualquier error que se hubiese cometido en desarrollo del conflicto y de la resistencia armada a que nos ha obligado el terror de las élites en el poder, estamos dispuestos a revisarlo en función de la reconciliación”, señaló la guerrilla, e insistió en que se debe convocar a una Asamblea Nacional Constituyente. Se refirió a que los medios colombianos exigen a las Farc pedir perdón. "Es el cálculo de la perfidia para ocultar a los verdaderos victimarios", estimó. "Perdón debe implorar un Estado que ha suprimido tantos seres humanos de manera desalmada con su política económica”, dijo el jefe guerrillero. (El Universal. 2013, Mayo 3).

El que denominan "error" ["hemos dicho que cualquier error que se hubiese cometido en desarrollo del conflicto...”] está expresado en pretérito pluscuamperfecto del subjuntivo, tiempo que le imprime un valor hipotético a la declaración: es probable que se hayan cometido errores, pero esta no es una aserción confirmada; es decir, las Farc se muestran como sujetos cognitivos y axiológicos al retener información y no declararse culpables.
Por otro lado, hay que señalar el uso de la tercera persona del singular ("cualquier error que se hubiese cometido") y no de la primera del plural (“cualquier error que hubiésemos cometido"): recordemos que, según Benveniste, la tercera persona del singular corresponde a la no-persona, la cual permite una discreción del "yo" en el enunciado para reducir las huellas de su presencia como enunciador. Esto es importante tenerlo en cuenta porque la forma como el enunciador se inscribe en su discurso contribuye también a la configuración de su ethos.

Esta imagen de víctima que han intentado construir las Farc no ha logrado, sin embargo, hasta la fecha, producir ningún efecto positivo frente la opinión pública. Por el contrario, las respuestas de los lectores que participan en los foros en línea manifiestan un rechazo total, recurriendo a argumentos ad hominen o de ataque personal.

\section{Estas escorias, bazofias, despojos de seres humanos dicen que ellos son las víctimas. ¿Qué estamos esperando de esos diálogos? Cada día nos ofenden más con sus rebuscadas peroratas.}

Hasta ahora la estrategia discursiva de las Farc al construir un ethos referido en el que hacen un autorretrato elogioso ha sido contraproducente y ha generado un fuerte rechazo, lo mismo que presentarse como víctimas e identificarse como pueblo.

Ahora bien, el ethos previo, que las Farc intentaron reparar construyendo una imagen de sí positiva al hablar de sí mismas como víctimas, y negando los vínculos con el narcotráfico y el secuestro, ha venido modificándose a medida que han avanzado las conversaciones. En sus últimas intervenciones ellas recurren a un cambio de estrategia discursiva al minimizar la auto-referencia y presentarse como una organización que conoce el país, que tiene propuestas que pueden llevar el campo a un mejor desempeño, que por décadas ha sido abandonado por el Estado; que escucha a las comunidades, al retomar sus propuestas para ser discutidas en la mesa de conversaciones. 
El resultado ha sido tan positivo que incluso algunos sectores políticos y la opinión pública calificada las han evaluado como razonables.

[...] las Farc hablan de la creación de un "fondo de tierras", conformado por "tierras provenientes de latifundios improductivos, ociosos o inadecuadamente explotados, tierras baldías, tierras apropiadas mediante el uso de la violencia y el despojo, y tierras incautadas al narcotráfico". La idea es que dichas tierras sean distribuidas entre "campesinos y mujeres, de manera prioritaria, al tiempo que mejorar las condiciones de propiedad y de producción de los pequeños y medianos propietarios, incluida la superación del microfundio. (Semana.com 2013, Enero 16).

Forista: por primera vez en muchos años veo que las Farc tienen una propuesta seria de política agraria, más allá de una retórica vaga sobre el marxismo o el socialismo, esta es una propuesta que en verdad se puede negociar y que de implementarse puede llegar a la tan anhelada paz.

Forista: Excelentes son las propuestas de las Farc. Responden al viejo anhelo del pueblo colombiano del derecho a la tierra y sus posibilidades de explotación. Tierra para los campesinos, tierra para los agricultores. Así se genera equidad.

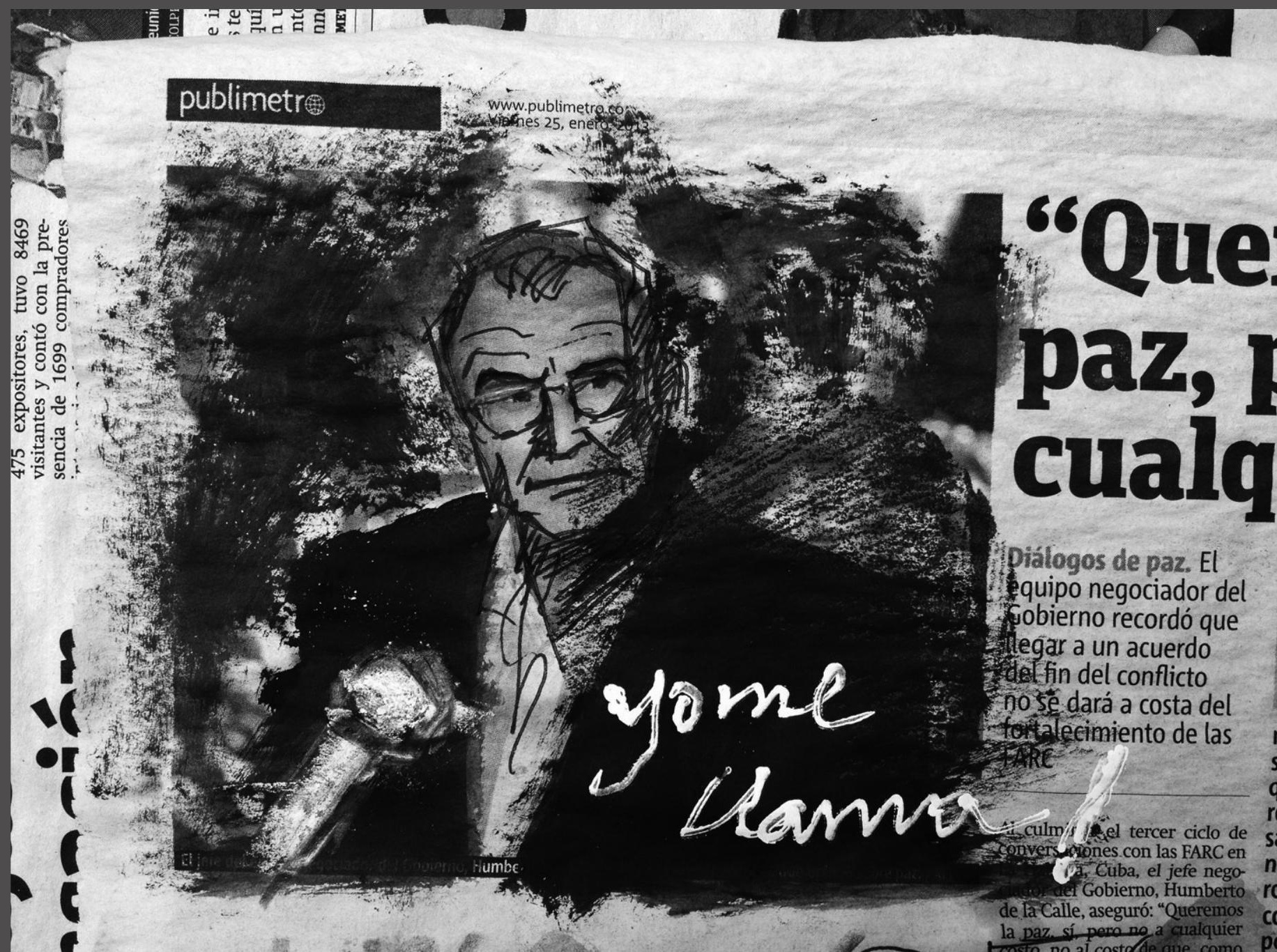


En una entrevista realizada por el diario El Espectador el 8 de junio de 2013, Andrés París, respondió así a la siguiente pregunta:

¿Cuál es el planteamiento de las Farc respecto a la participación en política?

Las Farc siempre han planteado el ensanchamiento de los espacios políticos para las fuerzas que se mueven en la oposición. Siempre hemos luchado por una apertura democrática y hemos confrontado el restringido sistema bipartidista que hay en Colombia. Este es, si se quiere, en el terreno político, uno de los aspectos que explican la aparición de la insurgencia armada. En el tema agrario, primer punto de la agenda, se abordaron las razones económicas de la confrontación armada en Colombia.

En el segundo punto tendremos que insistir en que el sistema antidemocrático también es una de las razones de este conflicto y llegar a una solución política implica abrir los horizontes de la democracia para todos los colombianos. Hablamos de participación en política no para la guerrilla, sino para todos. (Delegación de Paz FARC-EPÁG. Pueblo Colombiano: ¡Pa'la mesa! 2013, Junio 10).

En esta declaración las Farc construyen una imagen de sí como actores políticos y exponen con conocimiento de causa y un fuerte componente axiológico las causas que han llevado a la confrontación armada tanto en lo agrario como en lo político; en de su discurso exaltan el valor de la democracia y precisan que su lucha tiene como base la búsqueda de un país más democrático y que esta no es una conquista para el movimiento guerrillero sino para todos los colombianos.

Concluyamos diciendo que cuando las Farc dejan de lado el autorretrato elogioso y presentan propuestas económicas, sociales y políticas, el enunciatario infiere de su discurso el ethos de un sujeto cognitivo sensato, prudente, que muestra un profundo conocimiento sobre el tema agrario y político, pero también el ethos de un sujeto axiológico que promueve valores democráticos, de equidad y de justicia social; asimismo, podríamos decir que se presentan como un sujeto afectivo, benevolente, en tanto que se sitúan en el lugar del campesinado para construir propuestas que vayan en favor no de intereses particulares sino de todos los colombianos.

Para las Farc, el trabajo de reconfiguración del ethos debe ser una tarea permanente, si efectivamente quieren ser reconocidos como movimiento político en el que amplios sectores sociales puedan depositar su confianza.

\section{Notas}

\footnotetext{
${ }^{1}$ Magister en Comunicación Educativa. Estudiante del Doctorado en Humanidades, Cohorte: Análisis del discurso. Universidad del Valle.

${ }^{2}$ Retórica. Madrid: Gredos, 1999. Introducción, traducción y notas por Quintín Racionero. Todas las citas remiten a esta edición.
} 


\section{Referencias}

Aristóteles (1999). Retórica. Introducción, traducción y notas por Quintín Racionero. Madrid. Gredos. Amossy, Ruth (1999). Images de soi dans le discours. La construction de l'ethos. Paris. Delachaux et Niestlé.

(2010). La présentation de soi. Ethos et identité verbale. Paris. Presses

Universitaires de France.

Ducrot, Oswal (1986). El decir y lo dicho. Polifonía de la enunciación. Barcelona. Paidós. (1988). Polifonía y Argumentación. Cali: Universidad del Valle.

Eggs, Ekkehard (1999). Ethos aristotélicien, conviction et pragmatique moderne, en Amossy.

Maingueneau, Dominique (1996). Términos claves del análisis del discurso. Buenos Aires: Claves.

(1999). Ethos, scénographie, incorporación, en Amossy.

(2004). Le discours Littéraire. Paratopie et scène d'énonciation. Paris.

Armand Colin.

Kerbrat-orecchioni, Catherine (1999). La enunciación. De la subjetividad en el

lenguaje. Buenos Aires. Edicial.

Serrano, Orejuela Eduardo (2013). Enunciación, Narración y Argumentación en Crónica de una muerte anunciada. Cali: Tesis de doctorado inédita. Universidad del Valle. Colombia.

. (2013). Consideraciones semiolingüisticas sobre el ethos retórico. Documento inédito. Grupo de Investigación ADN, Cali. Universidad del Valle.

Woerther, Frédérique (2007). L'èthos aristotélicien. Gènese d'une notion rhétorique.

Paris. Libraire Philosophique.

\section{Recursos electrónicos}

Jiménez, Timoleón (“Timochenko") (2012, Septiembre, 5) Discurso de apertura de las conversaciones de paz. ANNCOL. FARC-EPÁG. Recuperado de http://anncol.eu/index.php/anncol

Delegación de paz FARC-EPÁG.(2013, Junio, 10) Pueblo Colombiano: ¡Pa 'la mesa! Entrevista al C. Andrés París por el Espectador. Recuperado de http: / /www.pazfarc-ep.org/index.php/ component/k2/item/1270-entrevista-al-comandante-andres-paris-por-el-espectador.html

Editorial. (2011, Mayo, 15). No se necesita reconocer conflicto con terroristas. Revista Semana. Recuperado de http://www.semana.com/politica/articulo/no-necesita-reconocer-

cconflicto-terroristas-uribe/239857-3

Editorial. (2013, Mayo, 3). Farc se "sienten" satisfechas con avance en negociaciones de paz. El Universal. Recuperado de http:/ / www.eluniversal.com.co/cartagena/nacional/farc-se-sienten-satisfechascon-avance-en-negociaciones-de-paz-118240

Editorial. (2013, Enero, 16) Las Farc destapan sus cartas en el tema agrario. Semana.com Recuperado de http: / /www.semana.com/nacion/articulo/las-farc-destapan-cartas-temaagrario/329827-3

Gallardo, Helio (2010) El Terrorismo desde América Latina. Enciclopedia Latinoamericana de Derechos Humanos. Brasil. http: / / heliogallardoamericalatina.info/index.php?option=com_content\&task $=$ view\&id=201\&Itemid $=9$

Uribe, Vélez Álvaro. (2003, Abril, 15) Discurso: Puesta en marcha de la brigada móvil $N^{\circ} 9$ Recuperado de http://web.presidencia.gov.co/discursos/discursos2003/abril/apiay.htm

Rainsford, Sarah. (2012, Septiembre, 13) Farc: Somos víctimas de esta guerra. BBC. Recuperado de http://www.bbc.co.uk/mundo/noticias/2012/09/120913_farc_entrevista_bbc_rodrigo_ granda_colombia_jp.shtml

Rueda de Prensa de las Farc en Oslo - Noruega.

Recuperado de http:/ / www.youtube.com/watch? $=$ xdpA2FAPsTM 